\title{
Achieving high quality surface of laminated glass-reinforced plastics during milling
}

\author{
Daniel Rychkov ${ }^{1, *}$, Dmitry Lobanov ${ }^{2}$, and Aleksey Kuznetsov ${ }^{1}$ \\ ${ }^{1}$ Bratsk State University, 40 Makarenko, Bratsk, 665709, Russian Federation \\ ${ }^{2}$ Ulianov Chuvash State University, 15, Moscow ave., Cheboksary, 128010, Russia
}

\begin{abstract}
Milling is one of the most common ways of workpiece machining, but obtaining a high quality surface of laminated composite materials is difficult due to their layered structure, high strength characteristics and low heat conductivity. This poses a problem of creating a milling technology that provides a high quality surface. This research investigates STEF - 1 glass-fiber plastic with fine grain structure processed on the equipment with high cutting speed. The object of the research is roughness $\mathrm{Ra}$ as a quality criterion. Our glass-fiber plastic milling experiments demonstrate that the surface quality depends to a large extent on the cutting modes and the wear level of the tool cutting edge which is determined by the size of the wear bevel on the flank surface. The blade of the cutting tool is established to wear unevenly during glass-fiber plastic processing as it interacts with two different materials. We recommend the wear bevel on the flank surface to be less than $0.35 \mathrm{~mm}$ to ensure the high quality of the laminated composite material surface. The cutting modes should be within the following range: feed per tooth is $0.15 \div 0.17$ $\mathrm{mm} /$ tooth, cutting depth is $0.5 \div 0.9 \mathrm{~mm}$, cutting speed is above $45 \mathrm{~m} / \mathrm{s}$, with the cutting part of the tool being made of high-strength instrumental materials.
\end{abstract}

\section{Introduction}

The main difficulty in composite materials processing is to ensure the high quality of the surface. It is connected with anisotropy of the composites properties as well as with the composites layered structure, high strength characteristics, low thermal conductivity and high hardness of the filler $[1-8]$. These features do not allow the use of traditional cutting technologies. Milling is one of the most common ways to form the surface of composite materials since it enables receiving both straight and shaped workpiece profile. Modular designs of milling cutters have demonstrated their efficiency as they allow to vary the material of the cutting part and to make replacement of cutting elements in case of wear or breakage $[9,10]$. The major requirements in the composite materials processing is the assignment of geometric parameters and cutting modes. They must provide the specified quality of the treated surface and correspond to the criteria of processing performance and wear resistance of the cutting tool.

* Corresponding author: rychkovda@gmail.com 
The recommendations [11 - 17] for some high-strength polymer composite materials processing suggest setting the maximum permissible cutting speed with minimum feed and depth of cutting. The geometric parameters of the cutting tool are recommended to be selected within the following range: face angle $\gamma=20 \div 30^{\circ}$, back angle $\alpha=10 \div 15^{\circ}$, the cutting point angle $\beta=50 \div 60^{\circ}$.

The major difficulty is the formation of high quality surfaces in polymer composites reinforced with strong fibers or fabrics. Incorrect selection of the cutting parameters results in high hairiness and roughness of the treated surface, as well as in burns, cracks and delamination at the edges of the product [18 - 23].

Consequently, the purpose of this research is to improve the milling technology so as to provide the high quality surface of the treated composites.

Achieving this goal necessitates investigation of how the milling modes influence the surface quality of hardened polymer composite materials.

\section{Methodology of experimental research}

The research is executed at milling of STEF-1 composite glass-fiber plastic as it possesses high-strength properties and is of fine grain structure, which allows using this composite as a construction material in the manufacture of machine parts for various purposes $[1,3,4]$.

The equipment for the conducted experiments was chosen with the view of the recommendations on cutting modes for polymeric composite materials. A 3D642E milling machine is selected to ensure high cutting speed. It allows setting the spindle speed up to $6000 \mathrm{rpm}$. The possibility of milling was provided by the installation of a sheet composite fixture on the machine. The extraction of the fine chips formed at cutting was performed by the device for local exhaust ventilation.

The variation of cutting modes was within the following range: feed per tooth $S_{z}=0.16 \div 0.33 \mathrm{~mm} /$ tooth, cutting depth $t=0.5 \div 1.5 \mathrm{~mm}$, cutting speed $V=45 \div 48 \mathrm{~m} / \mathrm{s}$. The modular cutter with inserts of VK $3 \mathrm{M}$ hard alloy was used as the cutting tool. The choice of the hard alloy brand is conditioned by the requirements for high-strength instrumental materials application since the cutting of glass-fiber plastic at the high processing speed results in the rapid wear of the tool cutting edge. The previous studies [21 -23] demonstrate the advantages of fine grain hard alloys in terms of wear resistance.

The roughness $R_{a}$ was chosen as the investigated parameter of the treated surface quality. It was measured by the complex for investigation of a surface topography (optical interferometer) Zygo NewViewTM 7300 intended for defining the microrelief parameters and the structure of the treated surface. The study by Carl Zeiss EVO50 scanning electron microscope was employed to detect the defects of the treated surfaces.

\section{Results and discussion}

The microrelief height of the surfaces received after milling varies from $8 \mu \mathrm{ms}$ $\left(S_{z}=0.16 \mathrm{~mm} /\right.$ tooth, $\left.t=0.5 \mathrm{~mm}\right)$ to $95 \mu \mathrm{ms}\left(S_{z}=0.33 \mathrm{~mm} /\right.$ tooth, $\left.t=1.5 \mathrm{~mm}\right)$ (Fig. 1, a). This indicates the significant impact of the cutting modes on the quality of the treated surface of composite materials.

The graph of the dependence between roughness and the cutting feed and depth (Fig. 1, b) shows that $R_{a}$ grows with increase of cutting modes. Thus, in case of semi-processing the roughness can be less than $2 \mu \mathrm{m}$.

The results of scanning microscopy (Fig. 2) show that the intensive delamination of the material begins when the feed $S_{\mathrm{z}}=0.33 \mathrm{~mm} /$ tooth, the cutting depth $t=1.5 \mathrm{~mm}$ and speed $V=45 \div 48 \mathrm{~m} / \mathrm{s}$. Under these conditions the binder is destroyed and the reinforcing fibers 
are pulled out of the workpiece body under the influence of high loads arising in the climb milling. The problem is also aggravated by the fact that after about 2 minutes of processing the cutting edge becomes significantly worn. Reducing the feed per tooth value to $S_{\mathrm{z}}=0.25 \mathrm{~mm} /$ tooth and cutting depth to $t=1.0 \mathrm{~mm}$ improves the quality of the surface to a little extent, with the defects still being significant. At $S_{\mathrm{z}}=0.16 \mathrm{~mm} /$ tooth and $t=0.5 \mathrm{~mm}$ the treated surface has no visible defects, and the section boundary between the binder and the matrix has clear contours.

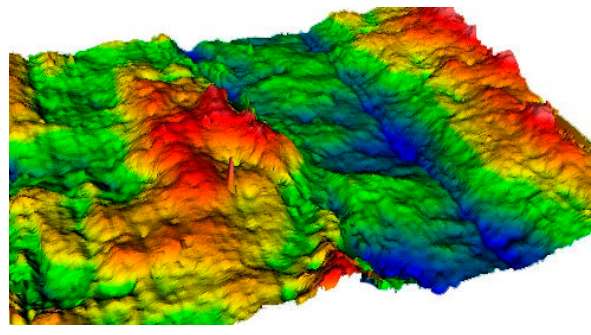

a)

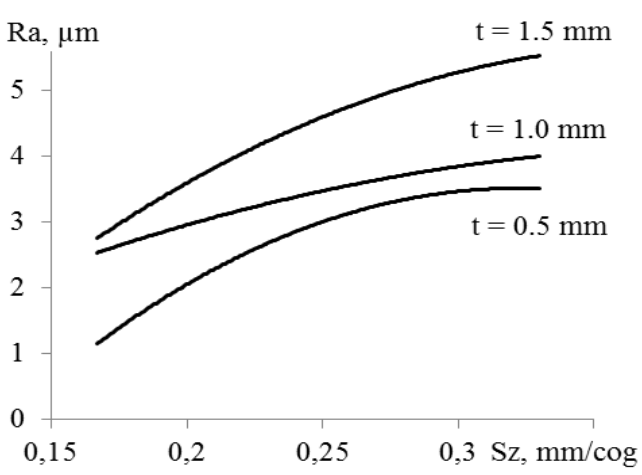

b)

Fig. 1. The roughness of the glass-fiber plastic surface after processing by a VK3M hard alloy: a - surface microrelief $\left(S_{z}=0.16 \mathrm{~mm} /\right.$ tooth; $\left.t=0.5 \mathrm{~mm}\right)$; $\mathrm{b}-$ the dependence of the roughness on the feed per tooth.

As a rule, the value of wear bevel on the tool flank surface $h_{\mathrm{z}}$ is taken as the criterion of wear during polymeric composite materials processing. This value depends on the requirements to the quality of the treated surface [21]. The dependence of the roughness on the value change in the wear bevel of flank surface is presented in Fig. 3, a.

This dependence is obtained at $S_{z}=0.16 \mathrm{~mm} /$ tooth, $t=0.5 \mathrm{~mm}$ and $V=45 \div 48 \mathrm{~m} / \mathrm{s}$. After the first pass the surface roughness of the glass-fiber plastic is $1 \div 1.5 \mu \mathrm{m}$. The wear bevel on the flank surface of the cutting tool $\left(h_{\mathrm{w}}\right)$ does not exceed $50 \mu \mathrm{m}$. With the increase of $h_{\mathrm{w}}$ the roughness of the treated surface grows and after reaching $h_{\mathrm{w}}=0.35 \mathrm{~mm}$ it is $5 \div 5.5 \mu \mathrm{m}$.

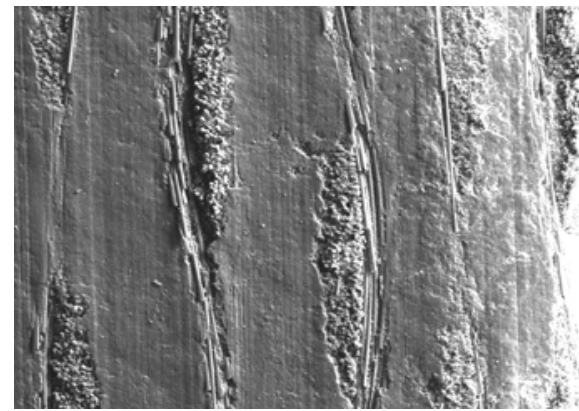

a)

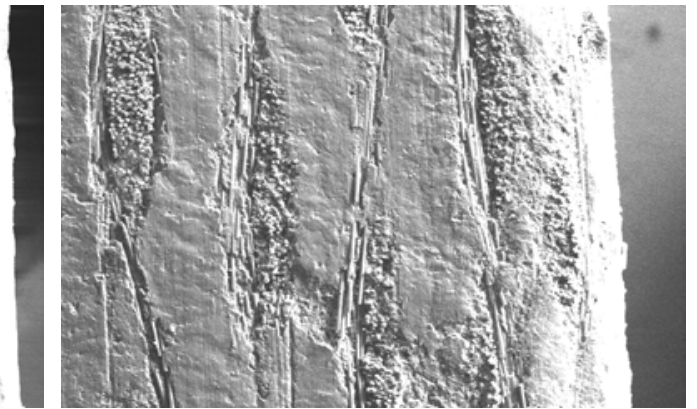

b)

Fig. 2. The glass-fiber plastic surface after 2 minutes of milling with VK3M hard alloy at $V=45 \ldots 48$ $\mathrm{m} / \mathrm{s}$ and at: a $-S_{z}=0.16 \mathrm{~mm} /$ tooth; $t=0.5 \mathrm{~mm} ; \mathrm{b}-S_{z}=0.16 \mathrm{~mm} /$ tooth; $t=1.5 \mathrm{~mm}$.

The roughness is heavily influenced by the wear of the cutting edge during milling. In the microscale the treated material has a heterogeneous structure (fig. 2) since, according to the technology of this composite manufacturing, the reinforcer is placed in layers and 
impregnated with the binder. As a result, the material acquires a laminated structure. In this case, the reinforcer is the fiberglass whose hardness and durability in many respects surpass similar properties of the binder, i.e. epoxy phenolic resin. Therefore, the blade of the cutting tool wears unevenly during glass-fiber plastic processing as it interacts with two different materials. Fig. 3, b demonstrates that the size of the wear bevel changes on the entire length of the cutting edge. The maximum size of $h_{\mathrm{w}}$ is observed in places of layered glass fibers location.
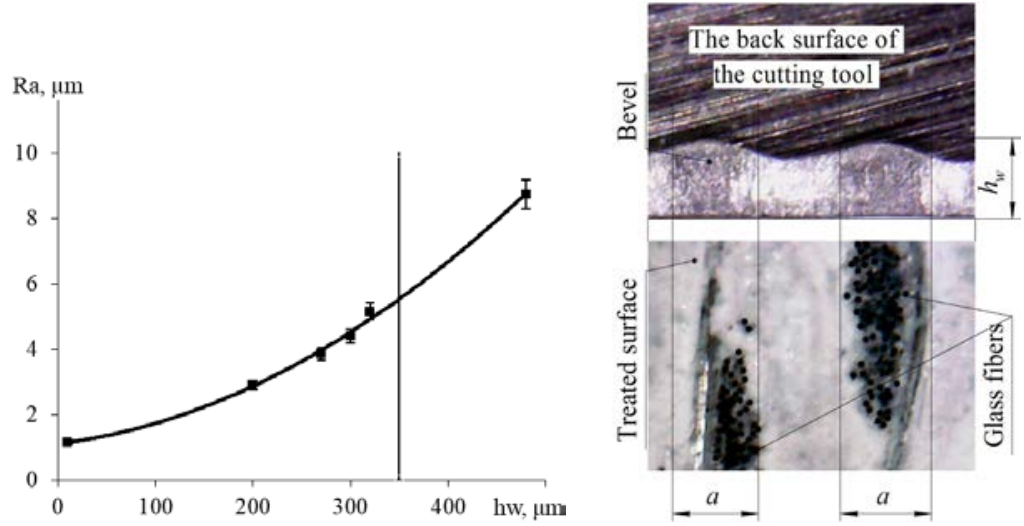

Fig. 3. Surface roughness dependence on the wear bevel of the flank surface.

\section{Conclusions}

Thus, the following conclusions and recommendations can be drawn from the research results:

- the surface roughness of the layered plastics depends both on the cutting modes and the degree of the cutting tool wear. The cutting tool wear bevel should not exceed $0.35 \mathrm{~mm}$ $\left(h_{\mathrm{w}}<0.35 \mathrm{~mm}\right)$ to obtain a satisfactory quality of the treated surface. When this value is reached, the cutting tool must be sharpened;

- wear of the cutting tools at layered composites milling occurs unevenly due to differences in the strength properties of the reinforcer and polymer binder. Therefore, physical and mechanical properties of the reinforcer in the treated composite material set condition for the choice of instrumental material;

- cutting modes for finishing machining are recommended to be set according to the required quality and performance within the following range: feed per tooth $S_{z}=0.15 \div 0.17 \mathrm{~mm} /$ tooth, cutting depth $t=0.5 \div 0.9 \mathrm{~mm}$ and cutting speed $V=45 \div 48$ $\mathrm{m} / \mathrm{s}$.

\section{References}

1. M. Georgescu, M. Sönmez, M. Niţuică, L. Alexandrescu, D. Gurău Thermally resistant polymer composites reinforced with fiberglass, Leather and Footwear Journal, v. 17, pp. 235-240 (2017).

2. M. Ramulu, H. Oberoi Edge finishing effects on mechanical properties of composite laminates, ASME International Mechanical Engineering Congress and Exposition, Proceedings (IMECE), v. 1, (2017) 
3. M. Stoica, F.-D. Anania, C.F. Bisu, M. Zapciu Research concerning the machinability of a fiber glass composite material, Annals of DAAAM and Proceedings of the International DAAAM Symposium, pp. 803-804 (2010).

4. J.L. Konzen Fiberglass-containing composite material, Applied Industrial Hygiene, v. 4, pp. 37-39 (1989).

5. F.M. Gallant, H.A. Bruck, S.E. Prickett, M. Cesarec Graded polymer composites using twin-screw extrusion: a combinatorial approach to developing new energetic materials, Composites Part A: Applied Science and Manufacturing, v. 6, pp. 957-969 (2006).

6. V. Dhand, G. Mittal, K.Y. Rhee, S-J. Park, D. Hui A short review on basalt fiber reinforced polymer composites, Composites Part B: Engineering, v. 73, pp. 166-180 (2015).

7. S.N. Grigoriev, A.N. Krasnovskii, K.V. Kvachev Investigation of impregnation fibrous materials in pultrusion process of polymer composite materials, International Polymer Science and Technology, v. 7, pp. 59-62 (2014).

8. L.A. Bokhoeva, V.E. Rogov, A.S. Chermoshentseva, D.V. Lobanov Stability and process of destruction of compressed plate of layered composite materials with defects, IOP Conf. Series: Materials Science and Engineering, v. 142, pp. 012077 (2016).

9. N.C. Engdahl CVD diamond coated rotating tools for composite machining, SAE Technical Papers, (2006).

10. D.V. Lobanov, A.S. Yanyushkin, D.A. Rychkov, N.P. Petrov Optimal organization of tools for machining composites, Russian Engineering Research, v. 2 (T. 31), pp. 156157 (2011).

11. C.F. Bivolaru, C. Opran, D.A. Murar Milling of polymeric sandwich composites products, Annals of DAAAM and Proceedings of the International DAAAM Symposium, pp. 1295-1296 (2011).

12. A.V. Gorokhovsky, J.I. Escalante-Garcia, G.Yu. Gashnikova, L.P. Nikulina, S.E. Artemenko Composite materials based on wastes of flat glass processing, Waste Management, v. 7, pp. 733-736 (2005).

13. E. Lemma, L. Chen, E. Siores, J. Wang Study of cutting fiber-reinforced composites by using abrasive water-jet with cutting head oscillation, Composite Structures, v. 1-4, pp. 297-303 (2002).

14. Y.A. Zaykin, U.P. Koztaeva Radiation-induced processes and internal friction in polymer-based composite materials, Radiation Physics and Chemistry, v. 4, 387-395 (2000).

15. V.N. Fomin, E.B. Malyukova, A.A. Berlin Criteria for optimization of processing and fabrication of polymer composite materials, Doklady Chemistry, v. 4-6, pp. 39-41 (2004).

16. J.L. Bailleul, V. Sobotka, D. Delaunay, Y. Jarny Inverse algorithm for optimal processing of composite materials, Composites Part A: Applied Science and Manufacturing, v. 8, pp. 695-708 (2003).

17. D.V. Lobanov, P.V. Arhipov, A.S. Yanyushkin, V.Y. Skeeba Physical-chemical processes of diamond grinding, IOP Conference Series: Earth and Environmental Science, v. 87 (8), pp. 082029 (2017).

18. E.D. Eneyew, M. Ramulu Effect of surface plies on the quality of holes produced when drilling CFRP composites, Technical Paper - Society of Manufacturing Engineers, v. 13 (64), pp. 18 (2013). 
19. I.G. Matis Methods and means of inspecting the quality of composite materials, Russian Journal of Nondestructive Testing, v. 4, pp. 277-285 (1991).

20. V.N. Bakulin, A.A. Larin, V.I. Reznichenkod Improving the quality of manufacture of polymer-composite products using computed tomography as a nondestructive-testing method, Journal of Engineering Physics and Thermophysics, v. 2, pp. 556-560 (2015).

21. A.S. Yanyushkin, D.A. Rychkov, D.V. Lobanov Rationalization of polymer composite materials processing by improving production efficiency, Procedia Engineering, v. 150, pp 942-947 (2016).

22. A.S. Yanyushkin, D.A. Rychkov The process of composite materials machining cutting tools profiling, Procedia Engineering, v. 206, pp 944-949 (2017).

23. D.A. Rychkov, A.S. Yanyushkin The methodology of calculation of cutting forces when machining composite materials, IOP Conference Series: Materials Science and Engineering, v. 142, pp. 012088 (2016). 